\title{
Future requirements of nuclear data for the handling, reprocessing and disposal of spent nuclear fuel
}

R.W. Mills

Nexia Solutions Ltd., B170, Sellafield Works, Seascale, Cumbria, CA27 0EF, UK

\begin{abstract}
This paper considers the decay heat and radiation source terms from a perspective based upon recent validation results for JEFF-3.1. Currently used fuel and reactor systems have sufficient measurements of irradiated fuel to justify safety cases, however until such measurements are available for novel systems these must be studied based upon the accuracy to which important nuclides can be determined from the basic nuclear data, both the individual nuclide concentrations calculated and their uncertainties must be considered and the subsequent effect on operation parameters and costs estimated. It should be noted that future facilities will need to be designed for both the calculated quantities and, typically, twice the uncertainty on the important operational parameters. Any nuclear data which dominates the uncertainties need to be identified as well as any biases so that improvements can be made to the basic nuclear data. An initial study is described considering only thermal reactors and some conclusions made about how these could be extended for novel systems.
\end{abstract}

\section{Introduction}

Currently the majority of commercial nuclear power production uses two industrially applied fuel cycles that are well quantified for safety and licensed within the nations concerned: the once through and the U/UOX/MOX recycling options in thermal reactors. These require the handling, transport and storage of the spent nuclear fuel; and for reprocessing the chemical separation of uranium and plutonium, and storage of the arising wastes in suitable material matrices for disposal.

Fuels and wastes from prototype reactors and chemical processing plants, and possible future reactor systems (e.g., GEN-IV, ADS, advanced reprocessing and transmutation technologies) will have to be dealt with by those responsible (e.g., private utilities or Governments) in current and future regulatory frameworks. These fuels may be considerably different from those currently handled; composed of different materials, be irradiated in different reactors, have different burn-up and cooling; and so will have different requirements for operations and safety. Higher decay heat requires either greater cooling for the fuel, or requires less fuel to be transported, stored or processed at one time in existing facilities leading to greater costs. Similarly, larger or significantly different radiation source terms (gamma-ray and neutron) would lead to similar issues with required shielding, again increasing costs. In addition, these fuels and wastes may be outside of currently accepted parameters for existing facilities and require new facilities to be built to accept them.

This paper considers the decay heat and radiation source terms from a theoretical perspective based upon recent validation results for JEFF-3.1, ref. [1]. Currently used fuel and reactor systems have sufficient measurements of irradiated fuel to justify safety cases, however until such measurements are available for new systems they must be studied based upon the accuracy to which important nuclides can be determined. Both the individual nuclide concentration calculated and its uncertainty must be considered and the subsequent effect on costs estimated. It should be noted that facilities will need to be designed for both the calculated quantity and, typically, twice the uncertainty on the important parameters. Any nuclear data which dominates the uncertainties need to be identified as must any biases so that improvements can be made.

\section{Safety and operational parameters}

\subsection{Situations to be considered}

After nuclear fuel is irradiated it is necessary to consider it in a range of situations through the fuel cycle. For direct disposal this would include:

- Storage at the reactor site, 30 days to 50 years.

- Transport to disposal or reprocessing sites, 3 to 50 years.

- Subsequent storage in water, 3 to 100 years.

- Dry storage, 50 to 300 years.

- Complete or dismantled irradiated fuel assembly in geological repository, 100 years onwards.

If reprocessing is included it is also necessary to consider:

- Fuel being mechanically and chemically processed.

- Separated product and waste streams.

- Separated products being stored, transported and processed prior to fabrication of fuel.

- Waste products being encapsulated stored and subsequently placed in a geological repository.

\subsection{Calculated parameters}

The properties of spent nuclear fuel are all dependent upon the composition of the fuel; the number densities of the nuclides present. There are several important applied nuclear physics parameters for operation and safety calculations:

- Decay heat for calculation of heat generation and material temperatures.

- Radiation dose from gamma-rays and neutrons through shielding.

- Neutron multiplication for criticality safety. 
In addition, the spent fuel inventory affects many other considerations associated with process chemistry, engineering design and decommissioning such as process effluents, waste forms, leaching from repositories, etc., which are beyond the scope of this paper.

\subsection{Important nuclides}

Many hundreds of nuclides are formed in nuclear fuel during irradiation and it is thus necessary to concentrate on the much smaller number of nuclides that contribute to the heating, radiation dose and criticality so that an analysis can be made of the effects of uncertainties on the nuclide inventories. The analysis below considers only thermal reactors but could be applied to other systems.

\subsubsection{Decay heat}

Using FISPIN, ref. [2], decay heat following a single fission was calculated for ${ }^{235} \mathrm{U},{ }^{239} \mathrm{Pu}$ and ${ }^{238} \mathrm{U}$ from 0.1 second to 30 years using JEFF-3.1 fission yield and decay data only. These nuclides were chosen as they dominate the number of fissions in typical thermal reactor fuels. The decay heat contributions of each nuclide greater than $0.5 \%$ were then listed for each cooling time and an error analysis carried out. It was assumed that the half-life, fission yield and recoverable energy per decay for each nuclide were independent in this analysis. It was necessary to assume that the uncertainty on the nuclide number density was the same as that on the cumulative yield; the cumulative yield uncertainties in JEFF-3.1 being calculated from the measured uncertainty on the chain yield and the estimated uncertainties on the independent yields decaying to the nuclide. It would be beneficial to carry out inventory calculations using a full error analysis considering all of the correlations in the data. Tables 1,2 and 3 show the results of this analysis for 90 days, 3 and 30 years. At these times fission product decay heat dominates spent fuel decay heat, at longer cooling times the actinide decay becomes more important and a full inventory calculation would be necessary.

For most nuclides the fission yield uncertainties dominate the uncertainty on the decay heat, except for ${ }^{103} \mathrm{Ru},{ }^{129,129 \mathrm{~m}} \mathrm{Te}$, ${ }^{144} \mathrm{Pr},{ }^{140} \mathrm{Ba},{ }^{103 \mathrm{~m}} \mathrm{Rh}$ and ${ }^{144} \mathrm{Ce}$, where the energy release per decay contributes significantly to the uncertainties.

It can be seen from these results that a good approximation of decay heat can be determined using a small number of nuclides for practical fuel transport and storage calculations. When reprocessing fuel, it should be noted that dissolved fuel, and insoluble species sent for waste disposal, will contain a different spectra of nuclides and more nuclides may need to be explicitly tracked to accurately calculate decay heat.

\subsubsection{Radiation dose}

A ranking of nuclides important for spent LWR fuel shielding was published in 2000, ref. [3]. The following table shows major contributors ( $>1 \%$ of total dose) for two specifications of spent LWR fuel assemblies and three cask types $(27 \mathrm{~cm}$ steel, $12.7 \mathrm{~cm}$ lead and $50 \mathrm{~cm}$ of concrete). It should be noted that ${ }^{60} \mathrm{Co}$ in the fuel assembly dominates at 5 years cooling
Table 1. Percentage contribution of nuclides to the fission product decay heat for a set of target materials at 90 days.

\begin{tabular}{llll}
\hline $\begin{array}{l}\text { Nuclide } \\
\end{array}$ & $\begin{array}{l}\text { U235 } \\
\text { (Thermal } \\
\text { fission) }\end{array}$ & $\begin{array}{l}\text { Pu239 } \\
\text { (Thermal } \\
\text { fission) }\end{array}$ & $\begin{array}{l}\text { U238 } \\
\text { (Fast } \\
\text { fission) }\end{array}$ \\
\hline${ }^{106} \mathrm{Rh}$ & $0.94 \pm 0.03$ & $16.74 \pm 0.41$ & $6.31 \pm 0.28$ \\
${ }^{95} \mathrm{Nb}$ & $23.65 \pm 0.26$ & $17.41 \pm 0.35$ & $20.55 \pm 0.35$ \\
${ }^{95} \mathrm{Zr}$ & $20.03 \pm 0.23$ & $14.75 \pm 0.3$ & $17.41 \pm 0.3$ \\
${ }^{103} \mathrm{Ru}$ & $5.46 \pm 0.16$ & $14.09 \pm 0.23$ & $11.56 \pm 0.23$ \\
${ }^{129 \mathrm{~m}} \mathrm{Te}$ & $<0.5$ & $0.51 \pm 0.21$ & $<0.5$ \\
${ }^{144} \mathrm{Pr}$ & $11.93 \pm 0.15$ & $11 \pm 0.12$ & $11.08 \pm 0.28$ \\
${ }^{129} \mathrm{Te}$ & $<0.5$ & $0.65 \pm 0.09$ & $<0.5$ \\
${ }^{140} \mathrm{La}$ & $6.7 \pm 0.1$ & $7.47 \pm 0.08$ & $6.9 \pm 0.1$ \\
${ }^{91} \mathrm{Y}$ & $12.9 \pm 0.12$ & $5.01 \pm 0.06$ & $9.99 \pm 0.33$ \\
${ }^{141} \mathrm{Ce}$ & $3.88 \pm 0.1$ & $3.97 \pm 0.06$ & $4.28 \pm 0.33$ \\
${ }^{89} \mathrm{Sr}$ & $9.61 \pm 0.12$ & $3.05 \pm 0.06$ & $6.77 \pm 0.18$ \\
${ }^{140} \mathrm{Ba}$ & $1 \pm 0.05$ & $1.12 \pm 0.06$ & $1.03 \pm 0.05$ \\
${ }^{103 \mathrm{~m}} \mathrm{Rh}$ & $<0.5$ & $0.93 \pm 0.06$ & $0.76 \pm 0.05$ \\
${ }^{144} \mathrm{Ce}$ & $1.07 \pm 0.01$ & $0.98 \pm 0.01$ & $0.99 \pm 0.03$ \\
${ }^{143} \mathrm{Pr}$ & $0.85 \pm 0.01$ & $0.77 \pm 0.01$ & $0.73 \pm 0.02$ \\
\hline Total & $98.02 \pm 1.53$ & $98.46 \pm 2.18$ & $98.35 \pm 2.7$ \\
\hline
\end{tabular}

Table 2. Percentage contribution of nuclides to the fission product decay heat for a set of target materials at 3 years.

\begin{tabular}{llll}
\hline \multirow{2}{*}{ Nuclide* $^{*}$} & $\begin{array}{l}\text { U235 } \\
\text { (Thermal } \\
\text { fission) }\end{array}$ & $\begin{array}{l}\text { Pu239 } \\
\text { (Thermal } \\
\text { fission) }\end{array}$ & $\begin{array}{l}\text { U238 } \\
\text { (Fast } \\
\text { fission) }\end{array}$ \\
\hline${ }^{106} \mathrm{Rh}$ & $7.56 \pm 0.21$ & $61.68 \pm 1.5$ & $37.79 \pm 1.67$ \\
${ }^{144} \mathrm{Pr}$ & $55.54 \pm 0.68$ & $23.55 \pm 0.25$ & $38.57 \pm 0.99$ \\
${ }^{125} \mathrm{Sb}$ & $<0.5$ & $1.08 \pm 0.14$ & $<0.5$ \\
${ }^{137 m} \mathrm{Ba}$ & $9.53 \pm 0.14$ & $5.54 \pm 0.08$ & $7.68 \pm 0.21$ \\
${ }^{90} \mathrm{Y}$ & $14.02 \pm 0.32$ & $2.08 \pm 0.06$ & $6.2 \pm 0.27$ \\
${ }^{144} \mathrm{Ce}$ & $4.96 \pm 0.07$ & $2.1 \pm 0.03$ & $3.45 \pm 0.09$ \\
${ }^{147} \mathrm{Pm}$ & $2.03 \pm 0.04$ & $1.15 \pm 0.02$ & $1.98 \pm 0.03$ \\
${ }^{137} \mathrm{Cs}$ & $2.88 \pm 0.04$ & $1.67 \pm 0.02$ & $2.32 \pm 0.06$ \\
${ }^{90} \mathrm{Sr}$ & $2.61 \pm 0.06$ & $<0.5$ & $1.15 \pm 0.05$ \\
\hline Total & $99.1 \pm 1.6$ & $98.9 \pm 2.2$ & $99.2 \pm 3.5$ \\
\hline
\end{tabular}

Table 3. Percentage contribution of nuclide to the fission product decay heat for a set of target materials at 30 years.

\begin{tabular}{llll}
\hline Nuclide $^{*}$ & $\begin{array}{l}\text { U235 } \\
\text { (Thermal } \\
\text { fission) }\end{array}$ & $\begin{array}{l}\text { Pu239 } \\
\text { (Thermal } \\
\text { fission) }\end{array}$ & $\begin{array}{l}\text { U238 } \\
\text { (Fast } \\
\text { fission) }\end{array}$ \\
\hline${ }^{90} \mathrm{Y}$ & $47.4 \pm 1.1$ & $20.9 \pm 0.6$ & $34.9 \pm 1.6$ \\
${ }^{137 m} \mathrm{Ba}$ & $33.2 \pm 0.5$ & $57.4 \pm 0.9$ & $44.6 \pm 1.2$ \\
${ }^{137} \mathrm{Cs}$ & $10.0 \pm 0.1$ & $17.3 \pm 0.2$ & $13.5 \pm 0.4$ \\
${ }^{90} \mathrm{Sr}$ & $8.8 \pm 0.2$ & $3.9 \pm 0.1$ & $6.5 \pm 0.3$ \\
\hline Total & $99.5 \pm 2.0$ & $99.5 \pm 1.8$ & $99.5 \pm 3.5$ \\
\hline
\end{tabular}

and this is produced by activation of steel components. As the ${ }^{59} \mathrm{Co}$ content of steels is often not known, to determine this introduces a significant bias to such calculations.

\subsubsection{Criticality calculations}

The selection of a range of important nuclides for criticality calculations is more difficult, however an OECD/NEA study on burn-up credit was published [5] that considered different 
Table 4. Percentage contribution of nuclides to dose at 5 years cooling.

\begin{tabular}{lcccccc}
\hline & \multicolumn{2}{c}{$\begin{array}{c}\text { Iron } \\
\text { cask }\end{array}$} & \multicolumn{2}{c}{$\begin{array}{c}\text { Lead } \\
\text { cask }\end{array}$} & \multicolumn{3}{c}{$\begin{array}{c}\text { Concrete } \\
\text { cask }\end{array}$} \\
\hline Burn-up $(\mathrm{GWd} / \mathrm{t})$ & 20 & 50 & 20 & 50 & 20 & 50 \\
Initial ${ }^{235} \mathrm{U}(\mathrm{wt} \%)$ & 3.0 & 4.5 & 3.0 & 4.5 & 3.0 & 4.5 \\
${ }^{60} \mathrm{Co}$ & 49 & 33 & 56 & 40 & 50 & 39 \\
${ }^{144} \mathrm{Pr}$ & 19 & 8 & 17 & 8 & 12 & 6 \\
${ }^{134} \mathrm{Cs}$ & 11 & 15 & 10 & 16 & 14 & 23 \\
${ }^{106} \mathrm{Rh}$ & 9 & 6 & 8 & 6 & 7 & 6 \\
${ }^{154} \mathrm{Eu}$ & 4 & 7 & 4 & 8 & 5 & 10 \\
${ }^{137 m} \mathrm{Ba}$ & 3 & 3 & $<1$ & $<1$ & 9 & 9 \\
${ }^{244} \mathrm{Cm}$ & 1 & 19 & 1 & 20 & $<1$ & 4 \\
${ }^{90} \mathrm{Y}$ & 1 & $<1$ & 1 & $<1$ & 1 & 1 \\
\hline
\end{tabular}

Table 5. Percentage contribution of nuclides to dose at 10,000 years cooling.

\begin{tabular}{lcccccc}
\hline & \multicolumn{2}{c}{$\begin{array}{c}\text { Iron } \\
\text { cask }\end{array}$} & \multicolumn{2}{c}{$\begin{array}{c}\text { Lead } \\
\text { cask }\end{array}$} & \multicolumn{3}{c}{$\begin{array}{c}\text { Concrete } \\
\text { cask }\end{array}$} \\
\hline Burn-up $(\mathrm{GWd} / \mathrm{t})$ & 20 & 50 & 20 & 50 & 20 & 50 \\
Initial ${ }^{235} \mathrm{U}(\mathrm{wt} \%)$ & 3.0 & 4.5 & 3.0 & 4.5 & 3.0 & 4.5 \\
\hline${ }^{240} \mathrm{Pu}$ & 54 & 40 & 53 & 40 & 44 & 34 \\
${ }^{242} \mathrm{Pu}$ & 25 & 47 & 25 & 46 & 21 & 41 \\
${ }^{239} \mathrm{Pu}$ & 15 & 7 & 16 & 8 & 12 & 5 \\
${ }^{214} \mathrm{Bi}$ & 4 & 4 & 5 & 4 & 16 & 11 \\
\hline
\end{tabular}

Table 6. Calculation of k-inf in a PWR infinite lattice considering different sets of nuclides.

\begin{tabular}{lc}
\hline Nuclide sets & $\begin{array}{c}30 \mathrm{GWd} / \mathrm{t} \\
1 \mathrm{yr} \text { cooled }\end{array}$ \\
\hline All actinides and fission products & 1.1080 \\
All actinides and no fission products & 1.2456 \\
Major actinides and no fission products & 1.2635 \\
All actinides and major fission products & 1.1402 \\
\hline
\end{tabular}

sets of nuclides for criticality studies. They considered the contribution of major actinides and fission products to the calculation of k-inf for PWR fuel in an infinite lattice. The major actinides were ${ }^{234,235,236,238} \mathrm{U}$ and ${ }^{239,240,241} \mathrm{Pu}$, and the major fission products were ${ }^{95} \mathrm{Mo},{ }^{99} \mathrm{Tc},{ }^{101} \mathrm{Ru},{ }^{103} \mathrm{Rh},{ }^{109} \mathrm{Ag},{ }^{133} \mathrm{Cs}$, $147,149,150,151,152 \mathrm{Sm},{ }^{143,145} \mathrm{Nd},{ }^{153} \mathrm{Eu}$ and ${ }^{155} \mathrm{Gd}$.

Although these results cannot tell us the individual importance of these nuclides for criticality calculations, they do show that this reduced set of 7 actinides and 15 fission products represent a significant part of the reactivity worth.

\section{Results of JEFF-3.1 validation}

Traditional validation exercises compare measured parameters (e.g., decay heat, gamma-dose, $\mathrm{k}_{\mathrm{eff}}$ ) against experiments and then set envelopes of operation so that problems cannot arise. An example of validating decay heat of PWR assemblies is given below. However to consider completely novel systems without expensive and time consuming experimentation it is necessary to consider the effects of the underlying uncertainties on nuclear data and spent fuel compositions. An example of validating spent fuel composition and it effect on the radiation dose from ${ }^{244} \mathrm{Cm}$ is shown as an example.
Table 7. Comparison of PWR assembly decay heat measurements with calculations using the JEFF-3.1 library.

\begin{tabular}{|c|c|c|c|c|c|}
\hline Reactor & $\begin{array}{l}\text { Initial } \\
{ }^{235} \mathrm{U} \\
(\mathrm{Wt} \%)\end{array}$ & $\begin{array}{l}\text { Burn-up } \\
(\mathrm{GWd} / \mathrm{t})\end{array}$ & $\begin{array}{l}\text { Cooling } \\
\text { (d) }\end{array}$ & $\begin{array}{l}\text { Meas } \\
\text { heat } \\
(\mathrm{W})\end{array}$ & $\begin{array}{c}\text { JEFF-3.1 } \\
\text { C/E }\end{array}$ \\
\hline Point Beach & 3.397 & 31.914 & 1635 & 724 & 0.97 \\
\hline Point Beach & 3.397 & 31.914 & 1635 & 723 & 0.97 \\
\hline Point Beach & 3.397 & 38.917 & 1634 & 921 & 1.00 \\
\hline Point Beach & 3.397 & 39.384 & 1633 & 931 & 1.00 \\
\hline Point Beach & 3.397 & 35.433 & 1630 & 846 & 0.96 \\
\hline Point Beach & 3.397 & 38.946 & 1629 & 934 & 0.99 \\
\hline Point Beach & 3.397 & 37.057 & 1630 & 874 & 0.99 \\
\hline Turkey Point & 2.556 & 28.430 & 962 & 1423 & 1.04 \\
\hline Turkey Point & 2.556 & 28.430 & 2077 & 625 & 1.01 \\
\hline Turkey Point & 2.556 & 26.485 & 963 & 1284 & 1.05 \\
\hline Turkey Point & 2.556 & 27.863 & 864 & 1550 & 1.05 \\
\hline Turkey Point & 2.559 & 25.595 & 1782 & 637 & 0.98 \\
\hline \multicolumn{3}{|c|}{$\begin{array}{l}\text { Mean and Standard Deviation } \\
\text { of } C / E \text { values }\end{array}$} & \multicolumn{2}{|c|}{$\begin{array}{l}\text { Point Beach } \\
\text { Turkey Point }\end{array}$} & $\begin{array}{l}0.98 \pm 0.02 \\
1.02 \pm 0.03 \\
1.00 \pm 0.03\end{array}$ \\
\hline
\end{tabular}

\subsection{PWR assembly heat decay}

For the transport, storage and geological disposal of spent fuel, it is important to have validation of the decay heat from complete assemblies. Schmittroth reported measurements of the decay heat from irradiated PWR assemblies together with comparisons against ORIGEN2 ref. [4]. This work considered 20 measurements with cooling times between 2.4 and 8.2 years for irradiations between 25 and $40 \mathrm{GWd} / \mathrm{t}$; note that 4 measurements reported as suspect in this report were ignored. The assemblies came from the San Onofre, Point Beach and Turkey Point reactors. The stainless steel fuel from San Onofre gave a calculated over experiment decay heat ratio $(\mathrm{C} / \mathrm{E})$ of 1.06 when assuming $1000 \mathrm{ppm}$ of cobalt as in ref. [4]. This type of stainless steel typically has between 120 and 1200 ppm of cobalt, using these figures it is possible to calculate mean decay heat $\mathrm{C} / \mathrm{E}$ values of 0.93 and 1.09 respectively. Unless the pre-irradiation cobalt content of the stainless steel can be discovered, it is thus not possible to draw any useful conclusions from the San Onofre results. Thus, only the Point Beach and Turkey Point data are considered in this work.

Decay heat calculations were carried out using the FISPIN code ref. [2] and JEFF-3.1 based decay data and fission yield libraries. In this work, JEFF-3.1 cross section libraries were generated using the reactor physics code WIMS9A and its associated cross section processing code TRAIL1A ref. [6]. The WIMS reactor physics models were based on design data reported in World Nuclear Industry Handbook ref. [7]. Minor uranium isotopes and fuel impurities were approximated by standard FISPIN methods. The structural materials for the assemblies were taken from ref. [4]. It should be noted that, to accurately model the activation of the end-fittings, a full 3D model would be necessary. In this work, a 2D approximation of the assembly was modelled.

The experimental decay heats and the FISPIN results are compared in table 7 . These results show good agreement between experiment and calculations for the JEFF-3.1 data, with all results within 5\%. The mean calculated over experiment 
decay heat ratio $(\mathrm{C} / \mathrm{E})$ for all assemblies was $1.00 \pm 0.03$. It should be noted that the uncertainty on the heat measurements are given as $\pm 2 \%$ and from the study above the calculated uncertainties on the decay heat are expected to be of a similar magnitude.

\subsection{Irradiated fuel composition}

As part of the "Actinide Research In A Nuclear Element" (ARIANE) programme, three UOX fuel samples were irradiated in the Goesgen PWR and then analysed at the Institute for Transuranium Elements Karlsruhe (ITU) and the Belgian Nuclear Research Centre (SCK.CEN) during the late 1990s refs. $[8,9]$. The results from the two laboratories could be compared to ensure the reliability of the measurements. The samples are referred to as GU1 (analysed at SCK.CEN), GU3 and GU4 (ITU). The liquor solution derived from sample GU3 was divided and analysed at both laboratories. These results are identified as GU3' (SCK.CEN) and GU3 (ITU). Enrichments were $3.5 \%$ and $4.1 \%$, and sample irradiations ranged from $29 \mathrm{GWd} / \mathrm{t}$ and $60 \mathrm{GWd} / \mathrm{t}$.

JEFF-3.1 WIMS, TRAIL and FISPIN cases were run to model the samples. The measured Nd148/fuel mass ratio was used to normalise the burn-up and thus the fuel ratings in the calculations. The ratios of the FISPIN predictions for selected nuclides important for fuel cycle applications are presented in table 8 . The experimental values cannot yet be reported outside of the programme's participants and thus only $\mathrm{C} / \mathrm{E}$ values are reported. From the mean and scatter of $\mathrm{C} / \mathrm{E}$ values for nuclides in the samples it is possible to estimate biases and uncertainties on spent fuel composition.

Using these results with the above sensitivities, it is possible to calculate the uncertainties on integral parameters. These biases can also be used to determine where nuclear data may be deficient. From this single set of data it is clear that obtaining estimates of the accuracy of the prediction of individual nuclides will give rise to large uncertainties on nuclides important for shielding and criticality. For example, the ${ }^{244} \mathrm{Cm}$ is $22 \%$ under predicted with a $14 \%$ uncertainty, thus from the sensitivities above, the calculated total dose from this fuel would be $\sim 4.4 \%$ low with a $\sim 2.8 \%$ uncertainty.

\section{Conclusion}

The calculation of decay heat from fuel assemblies using JEFF-3.1 gives good results and although nuclides are identified where improvements may be possible, this will have little benefit to existing operations, although it may assist future technology development.

The validation of nuclide concentrations show many important nuclides poorly predicted but the quality of the measurements is difficult to determine. It thus appears that the best way to further this study would be to use an inventory calculation tool that included a full error analysis including errors on all input nuclear data and operational parameters and that considered all the correlations in the data and its errors. This would require comprehensive errors to be included for all parameters in nuclear data libraries.
Table 8. Goesgen nuclide inventory $\mathrm{C} / \mathrm{E}$ ratios using JEFF-3.1 data.

\begin{tabular}{|c|c|c|c|c|c|}
\hline \multirow[t]{2}{*}{ Nuclide } & \multicolumn{4}{|c|}{ Sample } & JEFF-3.1 \\
\hline & GU1 & GU3' & GU3 & GU4 & Mean ; SD \\
\hline r90 & 0.77 & 1.03 & 0.98 & 0.99 & $0.94 ; 0.12$ \\
\hline 1095 & 1.00 & 0.88 & 0.94 & 0.97 & $0.95 ; 0.05$ \\
\hline c99 & 1.03 & 0.91 & 1.03 & 1.27 & $1.06 ; 0.15$ \\
\hline u106 & 1.08 & 0.87 & 0.47 & 0.85 & $0.82 ; 0.25$ \\
\hline 103 & 1.14 & 1.16 & 1.19 & 0.96 & $1.11 ; 0.10$ \\
\hline b125 & 1.90 & 1.98 & & & $1.94 ; 0.05$ \\
\hline 129 & & 0.99 & 0.97 & 0.90 & $0.96 ; 0.05$ \\
\hline s134 & 1.05 & 1.03 & 0.84 & 1.01 & $0.98 ; 0.10$ \\
\hline s135 & 1.05 & 1.07 & 1.01 & 1.14 & $1.07 ; 0.05$ \\
\hline s137 & 0.97 & 0.99 & 0.95 & 1.06 & $0.99 ; 0.05$ \\
\hline e144 & 1.06 & 1.07 & 1.06 & 1.08 & $1.07 ; 0.01$ \\
\hline n147 & 1.46 & 1.16 & 0.85 & 0.94 & $1.10 ; 0.27$ \\
\hline u154 & 2.27 & 1.80 & 1.57 & 1.60 & $1.81 ; 0.32$ \\
\hline $\mathrm{U} 236$ & 1.02 & 1.01 & 0.99 & 1.01 & $1.01 ; 0.01$ \\
\hline Np237 & & 0.90 & 0.84 & 0.74 & $0.82 ; 0.08$ \\
\hline u238 & 1.03 & 0.97 & 0.90 & 1.04 & $0.98 ; 0.06$ \\
\hline $\mathrm{u} 239$ & 1.18 & 1.04 & 1.04 & 1.07 & $1.08 ; 0.07$ \\
\hline 1240 & 1.02 & 0.98 & 0.96 & 0.99 & $0.99 ; 0.03$ \\
\hline u241 & 1.15 & 1.09 & 1.06 & 1.09 & $1.10 ; 0.03$ \\
\hline Pu242 & 0.92 & 1.00 & 0.91 & 1.02 & $0.96 ; 0.06$ \\
\hline $\mathrm{Pu}$ & 1.09 & 1.03 & 1.01 & 1.05 & $1.05 ; 0.04$ \\
\hline Am241 & 1.23 & 1.28 & 1.25 & 1.06 & $1.20 ; 0.10$ \\
\hline $\mathrm{Cm} 242$ & 0.98 & 0.93 & & & $0.96 ; 0.03$ \\
\hline $\mathrm{Cm} 244$ & 0.89 & 0.84 & 0.57 & 0.81 & $0.78 ; 0.14$ \\
\hline
\end{tabular}

The author gratefully acknowledges funding from the UK Nuclear Decommissioning Authority for this work.

\section{References}

1. JEFF Report 20, The JEFF-3.1 Nuclear Data Library, ISBN 9264-02314-3 (2006).

2. FISPIN is developed by Nexia Solutions Ltd., and distributed by Serco Assurance. The code is described by R.F. Burstall in FISPIN-A computer code for nuclide inventory calculations, ND-R-328I (1979).

3. B.L. Broadhead, I.C. Gauld, Rankings of Nuclide Importance in Spent Fuel Shielding Applications, ANS2000 Radiation Protection and Shielding Division Topical Conference, Spokane, Washington, 17-20 Sept. 2000.

4. F. Schmittroth, ORIGEN2 Calculations of PWR spent fuel decay heat compare with calorimeter data, HEDL-TME 83-32 UC-85 (1984).

5. M.C. Brady, M. Takano, H. Okuno, A. Nouri, E. Sartori, M.D. DeHart, Findings of an International Study on Burn-up Credit, Vol. 4, PHYSOR '96, in Proc. International Conf. on Physics of Reactors, Sept. 16-20, 1996, Mito, Japan.

6. Details of WIMS and TRAIL can be obtained from Serco Assurance, contact details are available on their web site www.sercoassurance.com/answers/.

7. Nuclear Engineering International World Nuclear Industry Handbook 1987 (ISSN 0029-5507).

8. D. Boulanger, M. Lippens, ARIANE International Program, Final report, AR 2000/15, Belgonucleaire, Dec. 2000.

9. T. Aoust, ARIANE International Program, Irradiation Data Report Parts 1, 2 and 3, AR 99/13, Belgonucleaire, July 1999. 